\title{
Application of artificial neural network for estimating the qualitative characteristics of cantaloupe melon and comparison with the regression model
}

\author{
Mahdi Ghasemi-Varnamkhasti ${ }^{*}$, Davood Ghanbarian ${ }^{1}$, Zahra Shojaei ${ }^{2}$, Abbasali Yadollahi ${ }^{3}$, \\ Ayat Mohammad Razdari', Reza Goli ${ }^{1}$ and Seyedeh Hoda Yoosefian ${ }^{4}$
}

${ }^{1}$ Department of Mechanical Engineering of Biosystems, Shahrekord University, Shahrekord. Iran.

${ }^{2}$ Faculty of Natural Resources, Shahrekord University, Shahrekord. Iran.

${ }^{3}$ Department of Agricultural Engineering, Payam Nour University, P. O. Box 81465-617, Kohandej, Isfahan, Iran.

${ }^{4}$ Department of Mechanical Engineering of Biosystems, University of Bu-Ali Sina, Hamadan, Iran.

${ }^{*}$ Corresponding author. Email: ghasemymahdi@gmail.com. Tel/fax: 03832324428.

Copyright (@ 2017 Ghasemi-Varnamkhasti et al. This article remains permanently open access under the terms of the Creative Commons Attribution License 4.0, which permits unrestricted use, distribution, and reproduction in any medium, provided the original work is properly cited.

Received 20th February, 2017, Accepted 8th March, 2017

\begin{abstract}
In this paper, the quality characteristics of melon was estimated by using color parameters and neural networks for three fertilizing stages (no fertilizer, fertilizing 5 and 10 ton/ha). For this purpose, chemical parameters including fructose, glucose and sucrose, and color parameters such as $L^{*}, a^{*}, b^{*}$ were studied. Physical characteristics under study were specific weight, mean firmness and skin. Chemical compositions include Brix, moisture content, titratable acidity, $\mathrm{pH}$ and ash. Results showed that the best determination coefficient for approximated equation of Brix is $R^{2}=0.96$ and the least standard error was found to be $S E=0.52$ related to glucose equation. According to the analyses done on the modeling data using neural network in Neuro Solutions software, the most appropriate network for fructose prediction was Feed for Multilayer perceptron with architecture of 4-12-12-1 and $R^{2}=0.99, \mathrm{MSE}=0.000324$. Therefore, for the estimation of quality characteristics for cantaloupe, neural network can be used successfully.
\end{abstract}

Key words: Quality, color, artificial neural network, cantaloupe melon.

\section{INTRODUCTION}

Cantaloupe melon is one of the most important garden plants with expanded range due to very diverse varieties and it is also grown in many areas of Iran (Salehi et al., 2011). The chemical compounds of cantaloupe depend on the varieties (cultivars) and its environmental conditions (Aktas et al., 2016). The changes in taste and texture often occur on the inner surface of the fruit that is related to the loss of cell walls and softening the flesh of the fruit. Changes of the taste are mainly related to the aromatic compounds, organic acids and soluble sugars (Beaulieu and Lea, 2007; Mccollum et al., 1988). Due to the high correlation between the quality of fruit and its sugar amount, accumulation of sugar during fruit growth is of particular importance. During the process of growth, primary storage of glucose and fructose changes into sucrose (Bianchi et al., 2016). Given that sugar levels do not increase after harvest, but the presence of sucrose with different proportions can be a source of different tastes in fruit with equal amounts of the sugar (Flores et al., 2001; Schaffer et al., 1987; Miccolis and Saltveit, 1991).

Increase in the production of cantaloupe has led to increase in the importance of the quality of this product in the food industry (Seymour and Mcglasson, 1993). Determination of quality characteristics is one of the new and favorite issues in food science and technology because being aware of the quality of food can provide more information about the storage, processing and quality monitoring of the fruit. For years, consumers determine the quality of the product through the conventional ways (Chachin and Iwata, 1988; Bianco and Pratt, 1977). In this method, comments of individual are 
very effective and there is not enough precision and speed accordingly. The presence of tasteless cantaloupe at the beginning of the season has caused more efforts to early ripening of products while unfortunately no success has been reported in this field so far. Quality is the most important marketing factor of the fruit (Barcelo et al., 2001). The degree of fruit quality is evaluated on the basis of the total sugar (mainly glucose, fructose and sucrose) in terms of brix degrees, or by sugar separation using liquid chromatography (Beaulieu and Lea, 2007).

Some studies have been conducted to determine the quality of cantaloupe and qualitative characteristics. Farhadi and Akbari (2001) evaluated the quantitative and qualitative characteristics and color of polyethylene soil cover cantaloupe. The results showed that the type of soil cover had a significant effect on yield of the product. In another study, determination of the cantaloupe size and stiffness changes during processing and storage stages was assessed. The results showed that the most stiffness was related to the unripe Shahabadi variety $(39.07 \mathrm{~N})$ while the ripened fruit of the Semsoori variety $(15.53 \mathrm{~N})$ had the lowest stiffness (Yunji et al., 2010; Ghanbarian et al., 2008). Also, Hakimi et al. (2012) found that the effect of chemical fertilizer on dry weight of leaves, stems, and fruit of cantaloupe and also biological yield of this fruit was significant at level of $1 \%$. The effect of manure was significant only on fruit yield and biological yield of cantaloupe. By increase in nitrogen fertilizer, dry weight of stem and leaf of cantaloupe as well as fruit yield and biological yield cantaloupe increased. The highest fruit yield and biological yield was obtained in $350 \mathrm{~kg}$ of chemical fertilizer along with 40 and 30 tons/ha (Hakimi et al., 2012).

According to the studies conducted on determination of the quality of cantaloupe and analysis of the results, it can be seen that the product has been crucial and requires further research in the food industry in terms of quality evaluation. Different methods for determination of the cantaloupe quality are time consuming and destructive. Furthermore, chemical tests for determining the quality are too expensive and labour intensive. This study was aimed to find a new method for estimating the quality of cantaloupe and the related physical characteristics of the fruit. According to the sources studied by the authors, determination of quality indicators of cantaloupe using color features and artificial neural networks in common is a novel and original idea.

\section{MATERIALS AND METHODS}

\section{Planting cantaloupe}

The tests were conducted at the Research Center for Agriculture and Natural Resources in Isfahan. Prominent cantaloupe variety (Semsouri) was selected for this study and the experiments were carried out with four replications. Fruits were selected based on the color and size.

\section{Color measurement of samples}

Color measurement of the samples was done using Hunter Lab method and a device with Brand name of USA- 5330- Colourquest Spectrophotometer, SNC. The color parameters include $L^{*}$ as the lightness level and $a^{*}$ as tend to reddish and yellowish and $b^{*}$ as the willingness to the yellowing index of blue and chroma (color density), respectively (Hakimi et al., 2012).

\section{Characterization (Brix, firmness and acidity using titration and $\mathrm{pH}$ )}

The sugar content was measured by Brix meter model ( $A$ CETI- Belalum Digital-Refractometer, Belgium) at a reference temperature of $20^{\circ} \mathrm{C}$. Real Brix index was corrected and obtained at a temperature of $15{ }^{\circ} \mathrm{C}$. Accuracy and precision of refractometer were 0.1 and $0.2 \%$, respectively. The acidity amount which can be tittered was obtained using AOAC method. The $\mathrm{pH}$ of the fruit flesh was measured using $\mathrm{pH}$ meter. The total amount of ash of samples was also obtained by keeping the fruit at a temperature of $450^{\circ} \mathrm{C}$ according to AOAC standards. Four replications were carried out for each experiment (AOAC 1984).

\section{Measurement of sugars using HPLC}

Primarily, sugars of flesh fruit of cantaloupe were extracted and were separately determined by HPLC according to Mendoza method. These sugars include glucose, fructose and sucrose. In order to extract sugar, $1 \mathrm{~g}$ lyophilized samples were homogenized in hot methanol (85\%) with stirring for 20 minutes. Then the mixture was centrifuged at $3500 \mathrm{rpm}$ for $20 \mathrm{~min}$ and the mixture was taken from the top of centrifuged samples (Seymour and Mcglasson, 1993). Sample was evaporated at $50^{\circ} \mathrm{C}$ in a rollers evaporator and the gained sample was obtained from the evaporator and then dissolved in distilled water again. The samples were filtered using a 0.45 micron filter and they (the volume of each sample $20 \mathrm{ml}$ ) were used for chromatographic analysis. In order to determine the quantity of sugar of each sample, standards of glucose, fructose and sucrose were used. To measure quantity of each sugar, standard charts of glucose, fructose and sucrose with concentrations 5 to $100 \mu \mathrm{g} / \mathrm{ml}$ were obtained (AOAC 1990).

\section{Structure of the neural network}

Multiple Layer Perceptron (MLP) network was used in this study. Figure 1 shows the schematic of qualitative estimations with the help of colorful features and neural 


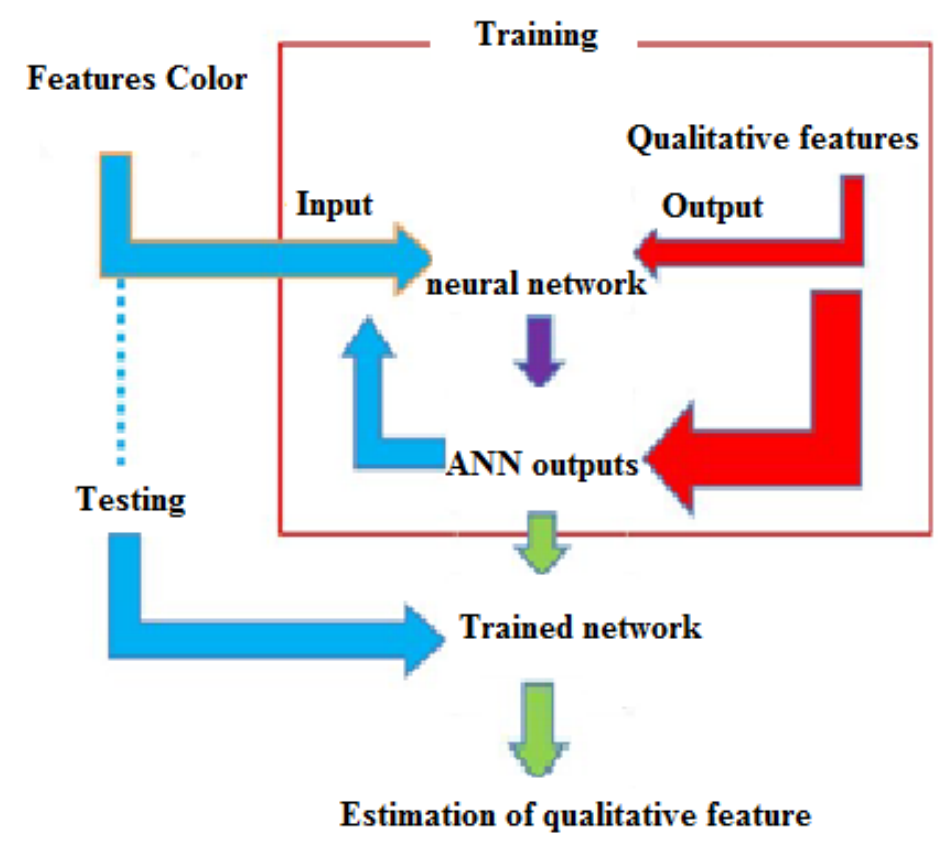

Figure 1. Schematic of estimation of qualitative features using colorful feature and neural networks.

network. In order to train the neural network, learning algorithm known as Multiple Layer Perceptron (MLP), Lundberg- Marquardt was used. The numbers of iterations of network (Epochs) which are the number of iterations of learning data were considered as 250 rounds for each network in this study. At the end, to assess and test the validity of the networks used, their performance was evaluated. Nero Solutions Version 5 Software was used for modeling the effect of amount of fertilizer on the qualitative indices. Two methods were used to evaluate the performance of the network.

\section{Coefficient of Determination}

As given in Equation (1), it is a dimensionless index that its best value is equal to one.

$$
R^{2}=\frac{\sum_{k=1}^{k} X_{k} Y_{k}}{\sqrt{\sum_{k=1}^{k} X_{k}^{2} \sum Y_{k}^{2}}}
$$

Where, $X_{K}$ is the observed values, $Y_{K}$ is the estimated values and $K$ shows the number of data. In order to find the networks with appropriate architecture using training algorithms, the mean square error (MSE) were used. In this equation, MSE shows the mean square error at training network, $S_{i p}$ is output of neuron model $I$, and $T_{i p}$ pattern is target output of $p$ (real) in the neuron $i$ and $p, n_{0}$ patterns are the number of neurons at the outer layers, $\mathrm{N}$ shows the number of output neurons, and also $\mathrm{m}$ is number of training patterns. Sigmoid logarithmic threshold functions and tangent sigmoid function were used in the hidden layer and output layer. Training, testing and validation of the network were carried out using the cantaloupe samples and $60 \%$ of the data to train, $25 \%$ for validation and finally $15 \%$ of data was used for testing the network.

$$
M S E=\left.\frac{\sum_{p=1}^{M} \sum_{i=1}^{N}\left(S_{i p}-T_{i p}\right)^{2}\lceil}{n_{p} \times n_{0}}\right|_{i p}=\left.\frac{\sum_{i p=1}^{n} S_{i p}}{n}\right|_{\text {---Eq. } 2}
$$

\section{Methods of statistical analysis of data}

Analysis of data obtained from the experiments was done using SPSS22 software and in the split plot block design and then ANOVA and Duncan tests were carried out considering the amount of fertilizer usage as the independent variable and each of the sugars, stiffness, weight of flesh, chroma index, Brix, specific gravity, moisture, $\mathrm{pH}$, titration acidity and ash as dependent variables. 
Res. J. Food Sci. Nutr.

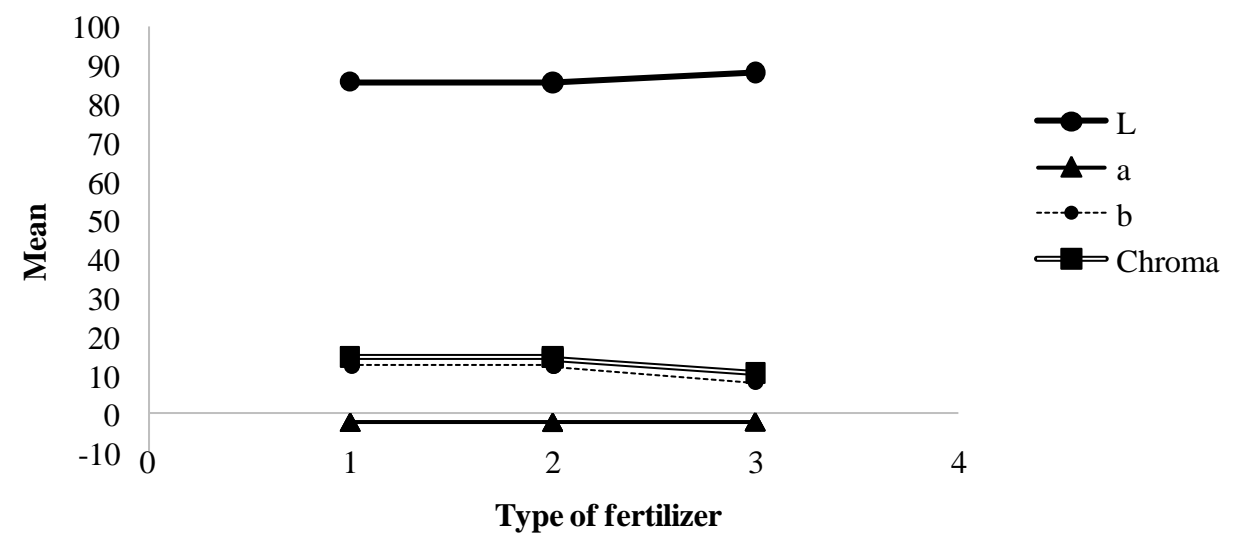

Figure 2. Parameters changes in $L^{*}, a^{*}, b^{*}$ and chroma with three types of fertilizer.

Table 1. Analysis of variance of the fertilizer on the physical and chemical indices

\begin{tabular}{lcccc}
\hline \multirow{2}{*}{ qualitative index } & \multicolumn{3}{c}{ Mean \pm Standard deviation } & \multirow{2}{*}{ Total } \\
\cline { 2 - 4 } & $\mathbf{0}$ & $\mathbf{5}$ (ton/hectare) & $\mathbf{1 0}$ (ton/hectare) & \\
\hline Fructose & $1.03 \pm 8.14^{\mathrm{ab}}$ & $1.47 \pm 0.87^{\mathrm{b}}$ & $0.64 \pm 0.53^{\mathrm{a}}$ & $1.04 \pm 0.66$ \\
Glucose & $0.79 \pm 0.10^{\mathrm{ab}}$ & $1.15 \pm 0.76^{\mathrm{b}}$ & $0.49 \pm 0.38^{\mathrm{a}}$ & $0.81 \pm 0.54$ \\
Sucrose & $0.19 \pm 0.21^{\mathrm{a}}$ & $0.56 \pm 0.62^{\mathrm{a}}$ & $0.33 \pm 0.36^{\mathrm{a}}$ & $0.36 \pm 0.43$ \\
Stiffness (N) & $25.20 \pm 8.26^{\mathrm{a}}$ & $27.31 \pm 6.83^{\mathrm{a}}$ & $22.55 \pm 31.10^{\mathrm{a}}$ & $25.02 \pm 8.44$ \\
Brix (\%) & $4.92 \pm 0.76^{\mathrm{a}}$ & $5.07 \pm 1.01^{\mathrm{a}}$ & $6.14 \pm 1.61^{\mathrm{a}}$ & $5.38 \pm 1.26$ \\
Moisture (\%) & $93.17 \pm 1.62^{\mathrm{ab}}$ & $92.24 \pm 1.3^{\mathrm{b}}$ & $92.49 \pm 1.25^{\mathrm{a}}$ & $93.30 \pm 1.53$ \\
pH & $5.35 \pm 0.39^{\mathrm{a}}$ & $5.57 \pm 0.36^{\mathrm{ab}}$ & $5.86 \pm 0.29^{\mathrm{b}}$ & $5.59 \pm 0.4$ \\
Weight mantle (g) & $720.41 \pm 145.55^{\mathrm{ab}}$ & $899.33 \pm 306.03^{\mathrm{b}}$ & $653.25 \pm 183.45^{\mathrm{a}}$ & $757.66 \pm 237.63$ \\
TA & $1.05 \pm 0.22^{\mathrm{b}}$ & $1.01 \pm 0.22^{\mathrm{b}}$ & $0.73 \pm 0.28^{\mathrm{a}}$ & $0.93 \pm 0.27$ \\
Dust & $98.97 \pm 0.61^{\mathrm{a}}$ & $99.26 \pm 0.17^{\mathrm{a}}$ & $99.20 \pm 0.25^{\mathrm{a}}$ & $99.14 \pm 0.39$ \\
Specific gravity & $0.76 \pm 0.13^{\mathrm{a}}$ & $0.73 \pm 0.12^{\mathrm{a}}$ & $0.72 \pm 0.16^{\mathrm{a}}$ & $0.73 \pm 0.13$ \\
\hline
\end{tabular}

\section{RESULTS AND DISCUSSION}

\section{Color analysis}

Figure 2 shows $L^{*}, a^{*}, b^{*}$ and chroma for cantaloupe in three types of fertilizers. The brightness of the cantaloupe had changes in various levels of fertilizations (Figure 2). Its maximum amount was observed for fertilizer at 5 tons/ha with a mean value of 88 .

\section{Analysis of qualitative characteristics}

Results of variance analysis of fertilizer amount on the physical and chemical parameters are shown in Table 1. The effect of fertilization on all parameters except Brix and specific weight was significant at the $5 \%$ level. Changes in the amount of fertilizer from zero to 10 tons/ha have led to ascending changes in $\mathrm{pH}$. However the opposite occurred for titration acidity. The results of the analysis of qualitative characteristics including fructose, glucose, sucrose, firmness, Brix, moisture, $\mathrm{pH}$, weight mantle, titration acidity, ash and density was consistent with the findings of Hakimi et al. (2012) and Arab salmani et al. (2011) who reported in their previous studies similar trends for the above substances. According to the studies, stiffness of cantaloupe is due to the various genetic traits such as type of fruit texture, excellence of skin thickness and meat. This is due to the changes in the Pectinic material of fruits in ripening process. Protopectin in green fruit changes during normal ripening of fruit and leads to reduced fruit firmness in the ripening process (Yunji et al., 2010).

\section{Determination of qualitative indicators using regression modeling}

Regression model was used to estimate the qualitative characteristics of cantaloupe using $L^{*}, a^{*}$ and $b^{*}$ parameters (Table 2). The best coefficient of determination was estimated for the Brix equation as $\mathrm{R}^{2}=$ 
Table 2. Regression model for estimation of qualitative index using parameters of $L^{*}, a^{*}$ and $b^{*}$.

\begin{tabular}{lccc}
\hline Index & Model & Standard Error (SE) & $\mathbf{R}^{2}$ \\
\hline Fructose & $0.01 \mathrm{~L}^{*}+0.5 \mathrm{a}^{*}+0.12 \mathrm{~b}^{*}$ & 0.63 & 0.78 \\
Glucose & $0.01 \mathrm{~L}^{*}+0.4 \mathrm{a}^{*}+0.08 \mathrm{~b}^{*}$ & 0.52 & 0.75 \\
Stiffness $(\mathrm{N})$ & $0.36 \mathrm{~L}^{*}+1.56 \mathrm{a}^{*}-0.28 \mathrm{~b}^{*}$ & 8.05 & 0.92 \\
Brix $(\%)$ & $0.02 \mathrm{~L}^{*}-2.07 \mathrm{a}^{*}-0.15 \mathrm{~b}^{*}$ & 1.23 & 0.96 \\
\hline
\end{tabular}

Table 3. Performance of artificial neural network for estimation the qualitative index.

\begin{tabular}{lccc}
\hline Estimation Test & Topology & Mean Square Error (MSE) & $\mathbf{R}^{2}$ \\
\hline Fructose & $1-12-12-4$ & 0.000132 & 0.96 \\
Glucose & $1-10-15-4$ & $5.09 \mathrm{e}-6$ & 0.91 \\
Stiffness $(\mathrm{N})$ & $1-15-15-15-4$ & 2.36 & 0.83 \\
Brix $(\%)$ & $1-10-15-4$ & 0.367 & 0.89 \\
\hline
\end{tabular}

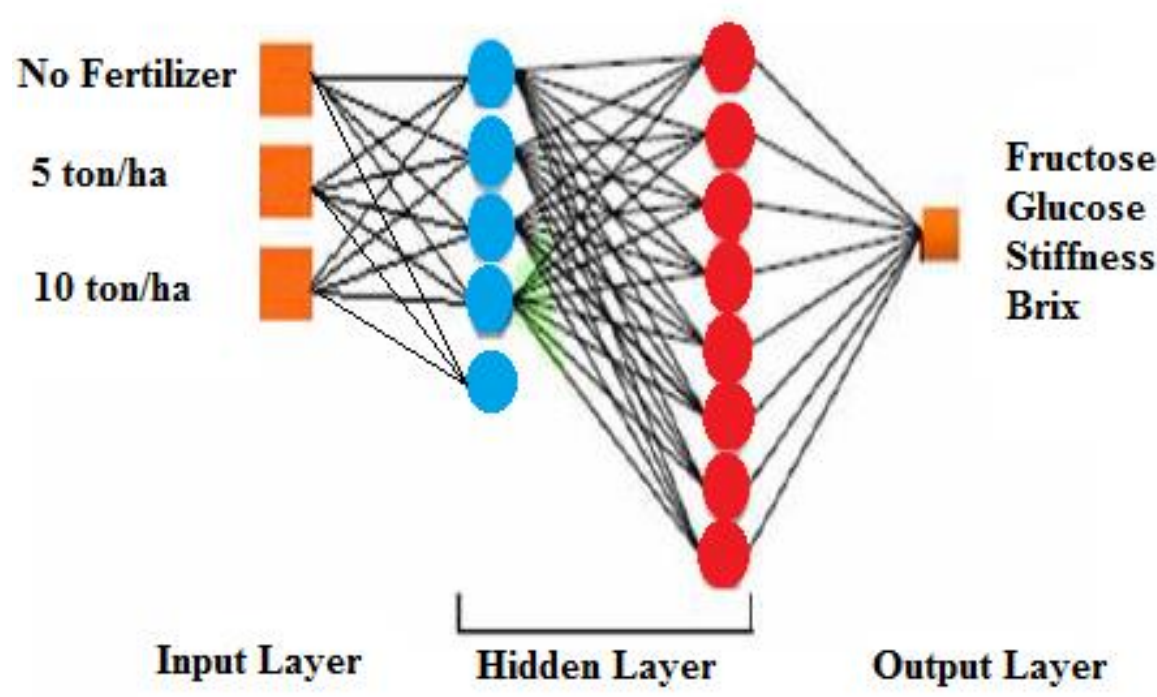

Figure 3. Structure of optimum neural network for prediction of qualitative indices.

0.96 and lowest standard error with a SE $=0.52$ is related to the glucose equation.

\section{Determination of the qualitative characteristics using neural network modeling}

The results of Artificial Neural Network to estimate the qualitative performance are presented in Table 3. Among different structures of the hidden layer, topologies have been presented which had the best outcome for prediction of quality. For these topologies, coefficient of variation $\left(R^{2}\right)$ and mean square error of training (MSE) has been presented. The mentioned conditions were ideal for training artificial neural network because the determination coefficient indicates full compliance of predicted points on the experimental data and also very low-error of network may represent the best network prediction that shows the compliance of network with the target. Figure 3 shows the optimum structure of neural network to predict the cantaloupe fructose. By testing various networks and studying the results, it was observed that the backpropagation algorithm with the mentioned topologies had the best results in terms of eligibility criteria for neural network. When the error is high during training or is implemented with inappropriate patterns, network learning curve line tends to the best meal and has distance from the goal line. It can be 
Res. J. Food Sci. Nutr.

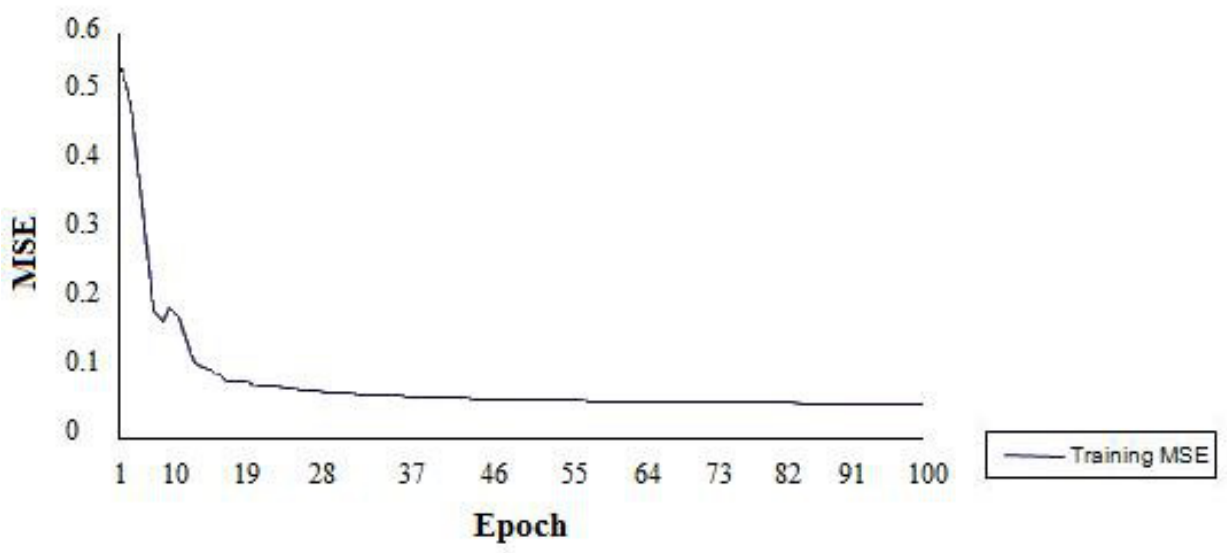

Figure 4. Changes of MSE for optimum network in the training data to estimation of fructose.

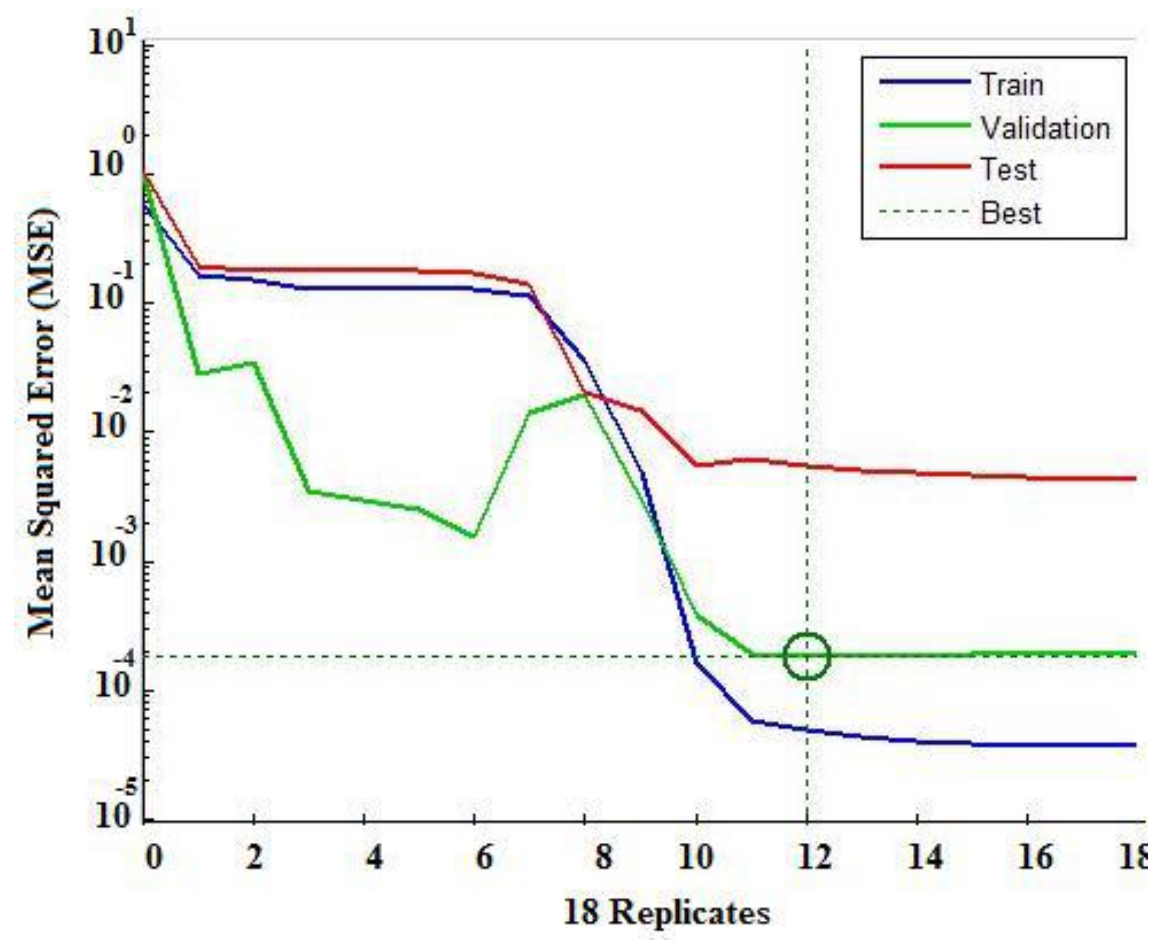

Figure 5. Changes of function error performance for optimal network using toolbox.

observed that the best and target lines are close together. Therefore, it can be said that network training has been carried out in the best way. Here the three sets, training set, a set for validation and a set for testing have been used. The graph (Figure 3) shows that MSE decreases by increasing the frequency of the training and an error is reduced by increasing number of courses. The network is matched on the training data.

Based on the analysis conducted on data modeling using neural network software of Nero Solution, Artificial Neural Network of Multilayer Perceptron by the type of propagation with the structure of $1-12-12-4$ is the most appropriate network for estimation of Fructose (Figure 4). The correlation coefficient of $R^{2}=0.99$ and MSE $=0.000324$ was obtained for the structure. Regression curves of software during training divides data that has been entered for network to three parts including training, testing, and evaluation and implements the training process on each part separately and eventually offers results in separate diagrams. Errors are also related to the decline in network performance during training (Figure 5). As frequency of Epochs increased, network error reduced, and in this model, the network achieved minimum errors after 12 Epochs (by 0.00018526 ). 


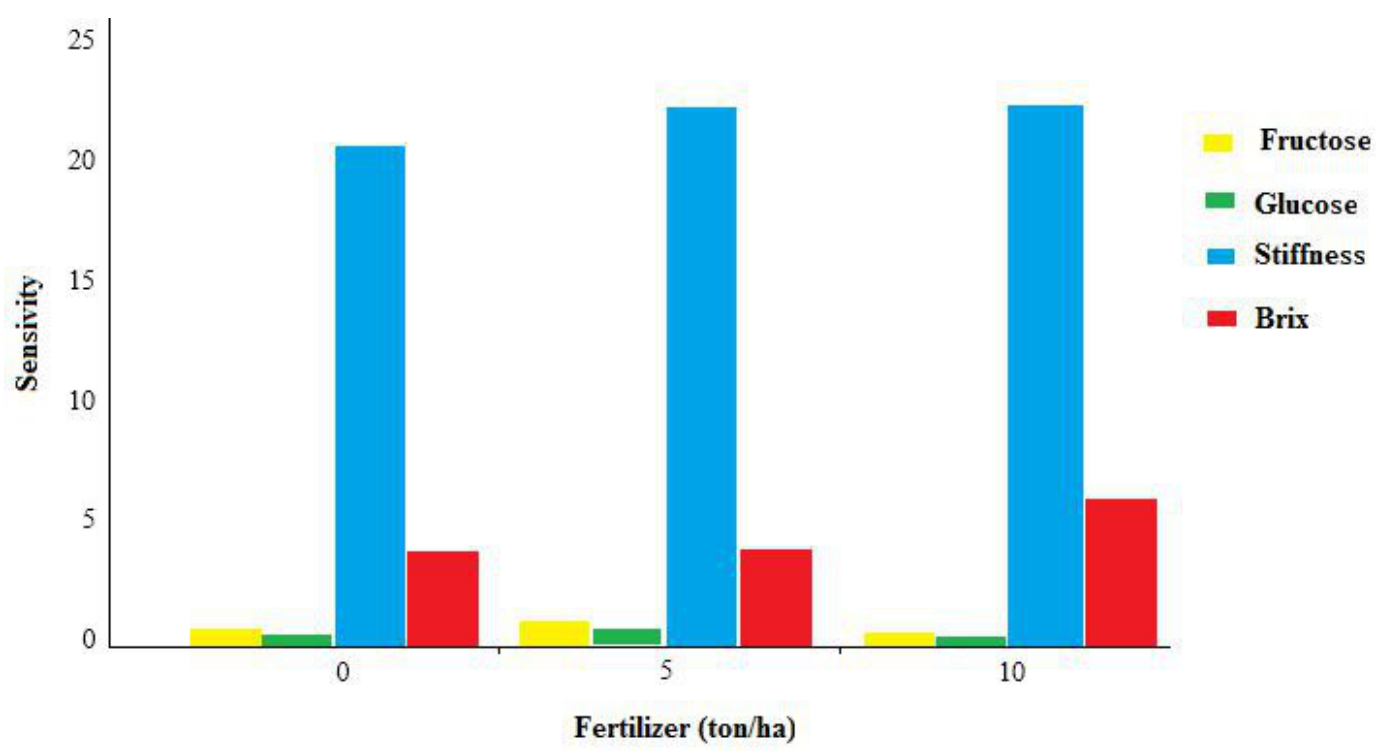

Figure 6. Result of sensitivity analysis by optimum neural network on melon during different amounts of fertilizer.

Furthermore in the 18th repeat in which the error of assessment data was begun, training was stopped.

In order to evaluate the influence of input parameters (The amount of fertilization) and identification of the most influential parameter value, sensitivity analysis test was performed on the network optimized. As it can be observed in Figure 6, among the input variables, 5 tons of fertilizer per hectare was the most effective factor in predicting qualitative indicators including fructose, glucose, firmness and brix.

\section{Conclusion}

One of the achievements of this study in terms of fruit harvesting is that ripening is the most important factor. If harvest is early, then cantaloupe is not sweet and flesh is firm. If it is later than usual then the flesh will be too soft and crisp. The factors that will determine the harvest time include cantaloupe color and the layers around the cantaloupe skin while if the stripes on the surface are green and the skin behind the bar cantaloupe is yellow or cream color then it is ready to harvest. The third factor is the smell of cantaloupe that begins after blossoming. In this research, the qualitative characteristics of cantaloupe were studied using artificial neural networks and the color indices were evaluated using neural network and regression methods. It was revealed the modeling using neural network method provides better results due to the least mean square error and the highest correlation coefficient in comparison with regression modeling. It should be noted that to provide a neural network model, a lot of data are required which may take a long time to collect data, but as the number of data channels increase for training, network's ability increases to generalize the results and simulation. Also, it was proved that since the amount of sugars in the cantaloupe on the commercial market is very important, the results showed that the highest amount of sucrose, fructose and glucose in the fertilization were obtained at 5 tons/ha treatment. Also, high levels of brix were obtained for the ripened cantaloupe using fertilization rate of 10 tons/ha.

For future studies, researchers can use modern methods for quality control such as spectroscopy, electronic nose and electronic tongue in combination with artificial intelligence techniques such as neural networks and genetic algorithms.

\section{CONFLICT OF INTEREST}

The authors declare that they have no conflict of interest.

\section{ACKNOWLEDGEMENTS}

The support of Shahrekord University (Grant procedure) is gratefully appreciated.

\section{REFERENCES}

Aktas, M., Sevik, S., Amini, A., \& Khanlari, A. (2016). Analysis of drying of melon in a solar-heat recovery assisted infrared dryer. Solar Energy, 137, 500-515.

AOAC. (1984). Official methods of analysis. 14thed. Arlington: Association of Official Analytical Chemists.

AOAC. (1990). Official methods of analysis.15thed. Arlington: Association of Official Analytical Chemists.

Arab salmani, K., Abedi, M., Jafari, p, Rafezi, R., \& shahriyari, 
D. (2011). Semsoori 88, a new high yielding cantaloupe cultivar for arid and semi-arid areas of iran (release of new cultivar). Seed and Plant Production Journal, 28(1), 121-123.

Barcelo, J., Nicolas, G., Sabater, B., \& Sanchez, R. (2001). Fisiologia vegetal. Ediciones Piramide, Madrid, Pp. 275-306.

Beaulieu, J. C., \& Lea, J. M. (2007). Quality changes in cantaloupe during growth, maturation, and in stored fresh-cut cubes prepared from fruit harvested at various maturities. Journal of the American society for Horticultural Science, 132(5), 720-728.

Bianchi, T., Guerrero, L., Gratacs-Cubarss, M., Claret, A., Argyris, J., Garcia-Mas, J., \& Horts, M. (2016). Textural properties of different melon (Cucumis melo L.) fruit types: Sensory and physical-chemical evaluation. Scientia Horticulturae, 201, 46-56.

Bianco, V. V., \& Pratt, H. K. (1977). Compositional changes in muskmelons during development and in response to ethylene treatment. Journal American Society for Horticultural Science.

Chachin, K., \& Iwata, T. (1988). Physiological and compositional changes in'Prince Melon'fruit during development and ripening. Bulletin of the University of Osaka Prefecture, Ser. B, Agriculture and Biology, 40, 27-35.

Farhadi, A., Akbari, M. (2001). Effects of irrigation and polyethylene mulch on the quality of cantaloupe. Journal of science and technology, 2(3), 161.

Flores, B. J., Mart Inez-Madrid, M. C., Anchez-Hidalgo, F. J., \& Romojaro, F. (2001). Differential Rind and Pulp Ripening of Transgenic Antitense ACC Oxidase Melon. Plant Physiology and Biochemistry, 39, 37-43.

Ghanbarian, D, Youneji, S, Fallah, S, Farhadi, A. (2008). Effect of broiler litter on physical properties, growth and yield of two cultivars of cantaloupe (Cucumis melo). International Journal of Agricultural and Biological Engineering, 6, 1814-9596.

Hakimi, L, Jam Nejad, M., Mesbah-Huda, N. (2012). Effect of manure and nitrogen fertilizer on quality characteristics of market-friendly cantaloupe. Third Congress of Horticultural Science. Pp. 1-4.
Mccollum, T. G., Huber, D. J., \& Cantliffe, D. J. (1988). Soluble Sugar Accumulation and Activity of Related Enzymes During Muskmelon Fruit Development. Journal of the American Society for Horticultural Science, 113, 399-403.

Mendoza, M. C. (1996). Cambios F. Isico-Qu Imicos Transcurridos En El Proceso De Maduraci-On De Dos Variedades De Mel on (Cucumis Melo L.). Bachelor Degree Thesis. Madrid: Complutense University.

Miccolis, V., \& Saltveit, M. E. (1991). Morphological and Physiological Changes during Fruit Growth and Maturation of Seven Melon Cultivars. Journal of the American Society for Horticultural Science, 116, 1025-1029.

Salehi, R. Kashi, A., Jung Myung, L., Delshad, M., Sung, G., Yoon-Chan, H. (2011). Seedling survival and growth of melon and Cantaloupe, pumpkin grafted on different rootstocks. Journal of Horticultural Science of Iran, 1, 1-9.

Schaffer, A. A., Aloni, B., \& Fogelman, E. (1987). Sucrose Metabolism and Accumulation in Developing Fruit of Cucumis. Phytochemistry, 26(7), 1883-1887.

Seymour, G. B., \& Mcglasson, W. B. (1993). Melons. In G. B. Seymour, J. E. Taylor, \& G. A. Tucker (Eds.), Biochemistry of Fruit Ripening. London: Chapman \& Hall.

Yunji, S. Ghanbarian, D., \& Farhadi, A. (2010). Cantaloupe fruit firmness changes during the procedure and store clothes. Sixth National Congress of Agricultural Machinery Engineering and Mechanisation, Pp. 1-7. 